\title{
El ejercicio por los funcionarios interinos de funciones reservadas tras la Ley 27/2013, de Reforma Local
}

\author{
Pedro Padilla Ruiz \\ Funcionario de carrera (T.A.G.) \\ Abogado
}

SUMARIO.- I. INTRODUCGIÓN. LAS FUNCIONES RESERVADAS GOMO FUNDAMENTO DE LA DISTINGIÓN ENTRE FUNCIONARIOS Y LABORALES. II. EL ESTABLECIMIENTO DE LO QUE DEBEN GONSIDERARSE FUNGIONES RESERVADAS EN EL ÁMBITO LOCAL. ANTECEDENTES DE LA REFORMA. III. EL CAMBIO EN LA CONFIGURACIÓN SUBJETIVA DE LAS FUNGIONES RESERVADAS A LOS FUNGIONARIOS LOCALES.- IV. CONGLUSIONES. BIBLIOGRAFÍA.

\section{RESUMEN.}

La nueva redacción dada al artículo 92.3 de la Ley 7/1985, reguladora de las Bases del Régimen Local, por la Ley 27/2013, de racionalización y sostenibilidad de la Administración Local, ha supuesto -al menos en teoría- que sólo los funcionarios de carrera puedan ejercer funciones que impliquen la participación directa o indirecta en el ejercicio de las potestades públicas o en la salvaguardia de los intereses generales. Esta cuestión va más allá de las funciones a ejercer por los funcionarios pues la reserva de funciones es también la nota diferenciadora respecto al personal laboral.

Este artículo analiza los motivos y las cuestiones que plantea esta novedosa restricción, así como las implicaciones que pudiera tener en el ámbito de las Entidades Locales y en particular en el ejercicio de las funciones que ejercen los funcionarios interinos.

PALABRAS CLAVE.

Función pública, empleo público, administración local, funciones públicas, funcionarios interinos 
ABSTRACT.

The new text of the article 92.3, Act 7/1985, regulating the Local System, by Act 27/2013, rationalization and sustainability of Local Government, has led -at least theoretically- that only career civil servants may exercise functions involving direct or indirect participation in the exercise of public powers or in safeguarding general interests. This issue goes beyond the functions to be exercised by officials as the reserve is also the distinguishing features note regarding labour workforce.

This article analyzes the reasons and issues raised by this original restriction, and the implications it may have in the field of Local Government and in particular the exercise of the functions exercised by interim civil servants.

\section{KEYWORDS.}

Civil service, public employment, local government, public powers, interim civil servants

\section{INTRODUCGIÓN. LAS FUNCIONES RESERVADAS COMO FUNDAMENTO DE LA DISTINCIÓN ENTRE FUNCIONA- RIOS Y LABORALES}

La tan largo tiempo esperada Ley 27/2013, de racionalización y sostenibilidad de la Administración Local ha traído, entre otras muchas novedades, una que quizás haya pasado desapercibida y a buen seguro pueda producir cierta inquietud, por cuanto ha supuesto un sorprendente cambio dentro de la regulación de las funciones a ejercer por los funcionarios públicos. Como sabemos, la ley les reserva aquellas con un valor específico en la garantía de los intereses generales, que justifican la necesaria objetividad, imparcialidad e independencia que les caracteriza y con que se protege su labor y configuran por otro lado el núcleo esencial de la actividad de las Administraciones Públicas.

Nos estamos refiriendo al giro dado por el legislador restringiendo el ejercicio de las funciones públicas reservadas a los funcionarios en exclusiva a los que sean "de carrera".

La cuestión tiene más trascendencia de la que en un primer momento se pueda inferir, pues no sólo afecta a las funciones que puedan desempeñar los funcionarios interinos que cubran plazas propias de los de carrera sino que además el ejercicio de funciones reservadas -por implicar la garantía de los intereses generales, como decimos- configura un elemento diferenciador con relación al personal laboral. Esta materia no ha sido abordada en nuestro ordenamiento hasta hace relativamente poco, pues por ejemplo, la Ley de Funcionarios Civiles del Es- 
tado sólo indicaba en su artículo 23.1 que corresponde "a los funcionarios de los Cuerpos Generales el desempeño de las funciones comunes al ejercicio de la actividad administrativa, con excepción de las plazas reservadas expresamente a otra clase de funcionarios" ", y la reserva de funciones se hacía entre Cuerpos de funcionarios, lo cual es del todo lógico dentro de un sistema de Cuerpos y donde el empleo público laboral era aún algo residual.

Por su parte, la Ley 30/1984, de Medidas para la reforma de la Función Pública, sólo hacía mención a tal reserva con carácter supletorio en su artículo 15.1 original al disponer que debían "especificarse aquellos puestos que, en atención a la naturaleza de su contenido, se reservan a funcionarios públicos". Posteriormente, por declararse dicho inciso inconstitucional ${ }^{2}$, la Ley 23/1988, de Modificación de la Ley de Medidas para la Reforma de la Función Pública, actualiza parte de su articulado indicando que con carácter general los puestos de trabajo en las Administraciones públicas serán desempeñados por funcionarios, exceptuando de esta regla general determinados puestos, que podrían ocuparse por personal laboral ${ }^{3}$, dándose ya carta de naturaleza a la utilización de esta clase de empleados para desempeñar determinados puestos de trabajo.

Y a partir de aquí es cuando comienza a alcanzar mayor énfasis la cuestión de la nota distintiva entre funcionarios y laborales pues, realizando ambos en muchos casos las mismas tareas, no parecía tener mucho sentido que se sometan a regímenes jurídicos diferentes.

Finalmente, el Estatuto Básico del Empleado Público (EBEP) ha tratado de unificar esos dos grandes tipos de personal al servicio de las Administraciones Públicas a través del concepto "empleados públicos". Como sabemos, el EBEP se creó en virtud del mandato constitucional establecido en el artículo 103.3, que imponía la obligación de regular mediante un Estatuto de los funcionarios públi-

${ }^{1}$ El artículo 23.2 aclaraba cuáles eran esos Cuerpos Generales: "Los Cuerpos generales de Administración civil son los siguientes: Técnico, Administrativo, Auxiliar y Subalterno". Por su parte, la citada Ley distinguía de aquellos los Cuerpos Especiales, que según su artículo 24 son "los que ejercen actividades que constituyen el objeto de una peculiar carrera o profesión y los que tienen asignado dicho carácter por razón de las circunstancias concurrentes en la función administrativa que les está encomendada".

${ }^{2}$ La STC 99/1987, de 11 de junio, declaró la inconstitucionalidad y nulidad del último inciso del artículo 15.1, entre otros.

${ }^{3}$ La misma Ley 23/1988 añade un apartado dos a la Disposición Transitoria decimoquinta de la Ley 30/1984, permitiendo la funcionarización de aquellos laborales que vinieran ocupando puestos reservados a funcionarios a la entrada de vigor de ésta. 
cos el régimen jurídico de este tipo de personal al servicio de las Administraciones Públicas ${ }^{4}$. Así, el artículo 8 EBEP define los empleados públicos como aquellos que "desempeñan funciones retribuidas en las Administraciones Públicas al servicio de los intereses generales", para seguidamente incluir en esta definición a los funcionarios de carrera o interinos, los laborales fijos o indefinidos ${ }^{5} \mathrm{y}$ al personal eventual.

Esto plantea una primera duda, pues si ambos tipos de personal desempeñan funciones al servicio del interés general, ¿dónde se encuentra la diferencia entre contar con laborales, con un régimen jurídico más flexible, o con funcionarios?

La cuestión no carece de importancia pues volviendo al EBEP, ya desde su exposición de motivos e incluso antes, a través del Informe de la Comisión para el estudio y preparación del Estatuto Básico del Empleado Público, se reconoce la imposibilidad de crear un régimen totalmente unificado para ambos tipos de personal debido a sus peculiaridades y a la doctrina del propio Tribunal Constitucional al reconocer esas diferencias ${ }^{7}$. En este sentido, hemos de tener en cuenta que dicho Tribunal interpretó inicialmente que el artículo 103.3 de la Constitución establecía una preferencia por la utilización de personal funcionario (relación estatutaria de empleo público ${ }^{8}$, preferencia que, como recuerda el Informe de la Comisión, no se ha respetado en la práctica ${ }^{9}$ y también ha sido suavizada posteriormente.

${ }^{4}$ El texto del artículo 103.3 CE es el siguiente: "La ley regulará el estatuto de los funcionarios públicos, el acceso a la función pública de acuerdo con los principios de mérito y capacidad, las peculiaridades del ejercicio de su derecho a sindicación, el sistema de incompatibilidades y las garantías para la imparcialidad en el ejercicio de sus funciones".

${ }^{5}$ Que históricamente se llegaron a llamar obreros de plantilla. Decreto 784/1961, de 8 de mayo, que regula la jubilación en la Administración local (BOE n 126, de 27 de mayo, p. 8007).

${ }^{6}$ CANTERO MARTÍNEZ, J., "Criterios para la clasificación del empleado público: ¿funcionario o laboral?", en Revista Vasca de Gestión de Personas y Organizaciones Públicas, n 5, 2013, pp. 82-99.

${ }^{7}$ Así, la temprana STC 57/1982, en su Fundamento Jurídico $9^{\circ}$ lo hace constar con estos términos: "sin duda la Carta fundamental parte del hecho de tratarse de situaciones diversas por su contenido, alcance y ámbito diferente de función y actuación, y por eso independiza y diversifica su regulación legislativa, sometiéndolos a regulaciones diferenciadas que no parecen irrazonables". También STC 129/1987; o STS de 25 de octubre de 1997.

${ }^{8}$ STC 99/1987, de 11 de junio, ya mencionada.

${ }^{9}$ INAP, Estatuto básico del empleado público: informe de la Comisión, Madrid, INAP, 2005. p. 21. 
Posteriormente se ha discutido mucho sobre el sentido que quiso darle el texto constitucional al término funcionarios públicos y si se restringía sólo a este tipo de empleados ${ }^{10} \mathrm{o}$ se podía incluir también al personal laboral, más si tenemos en cuenta que desde hacía tiempo se estaba llevando a cabo la contratación de estos, sometidos a su propio régimen jurídico privado ${ }^{11}$ aunque sin establecer diferencias o criterios para la elección de uno u otro tipo de personal, lo que coadyuvó a los innumerables problemas teórico-prácticos en la materia.

El EBEP ha resuelto en parte la cuestión de la dualidad al imponer en su artículo 9.2 que,

En todo caso, el ejercicio de las funciones que impliquen la participación directa o indirecta en el ejercicio de las potestades públicas o en la salvaguardia de los intereses generales del Estado y de las Administraciones Públicas corresponden exclusivamente a los funcionarios públicos, en los términos que en la ley de desarrollo de cada Administración Pública se establezca.

Así pues, será el ejercicio de esas funciones que conformarían el núcleo de las potestades y fines de las Administraciones Públicas las que configuren la nota diferenciadora entre funcionarios y laborales, pero dentro de aquellos estableciendo otro límite, por cuanto sólo se permite el acceso a la función pública de los nacionales españoles cuando las funciones supongan ejercicio de autoridad o la salvaguarda de los intereses del Estado o de las Administraciones Públicas ${ }^{12}$. Sin embargo, la peculiar redacción del artículo 9.2 también plantea la duda en cuanto a qué diferencia hay entre desempeñar funciones al servicio de los intereses ge-

${ }^{10}$ Vid. ESCRIBANO TESTAUT, P., Fundamentos del sistema constitucional de empleo público (un estudio de los artículos 103.3 y 23.2 de la Constitución), Universidad Autónoma de Madrid, Tesis Doctoral, 1998; DE SANDE PÉREZ BEDMAR, M., Empleo y prestación de servicios en la Administración Pública, Valladolid, Lex Nova, 2006; MAIRAL JIMÉNEZ, M., El derecho constitucional a la igualdad de tratamiento jurídico en el empleo público: (un estudio de los problemas jurídicos derivados de la dualidad de regímenes...), Universidad de Granada, Tesis Doctoral, 1990.

${ }^{11}$ Incorporación que permitió expresamente el artículo 7.1 de la ley de Funcionarios Civiles del Estado de 1964 al prever la inclusión de personal laboral en las Administraciones Públicas: "Son trabajadores al servicio de la Administración civil los contratados por ésta con dicho carácter, de acuerdo con la legislación laboral, que les será plenamente aplicable”.

${ }^{12}$ Art. 57.1 EBEP: "Los nacionales de los Estados miembros de la Unión Europea podrán acceder, como personal funcionario, en igualdad de condiciones que los españoles a los empleos públicos, con excepción de aquellos que directa o indirectamente impliquen una participación en el ejercicio del poder público o en las funciones que tienen por objeto la salvaguardia de los intereses del Estado o de las Administraciones Públicas". 
nerales que establece el artículo 8 de manera común para funcionarios y laborales, y la reserva a aquellos de funciones que impliquen "salvaguardia de los intereses generales".

Por tanto, en este estudio nos encontramos con carácter previo con que las funciones reservadas configuran un peculiar y en principio más destacado elemento distintivo entre funcionarios y laborales. La cuestión es saber exactamente cuáles sean dichas funciones, pues no se establecen en el EBEP ni tampoco anteriormente.

Como indica el Informe de la Comisión, la reserva de funciones públicas a funcionarios puede establecerse sobre la base de criterios generales como los que se establecen en el artículo 92.2 de la Ley de Bases del Régimen Local, es decir, la "mejor garantía de la objetividad, imparcialidad e independencia en el ejercicio de la función ${ }^{13}$.

Será mediante ley ordinaria cuando posteriormente se delimite lo que en cada caso deban entenderse por tales como dispuso, por ejemplo, la Ley 30/1984.

\section{EL ESTABLECIMIENTO DE LO QUE DEBEN CONSIDE- RARSE FUNGIONES RESERVADAS EN EL ÁMBITO LO- CAL. ANTECEDENTES DE LA REFORMA}

La mejor pista de lo que el legislador ha considerado como funciones reservadas a los funcionarios ${ }^{14}$ nos la ofrece ciertamente la legislación de régimen local, pues aunque sea de manera restringida a este ámbito y para su personal encontramos una buena especificación de lo que se entiende por dichas funciones, y que nos pueden ayudar a desarrollar esta materia, siendo precisamente donde se ha producido el giro legislativo que nos ha traído a escribir estas páginas. Esa concreción de las funciones reservadas la establece el artículo 92 de la Ley $7 / 1985$.

${ }^{13}$ INAP, Op. Cit. p. 52.

${ }^{14}$ Sobre las funciones reservadas en el EBEP puede leerse a VERA TORRECILLAS, R.J., "Las funciones reservadas y el Estatuto Básico del Empleado Público: algunas consideraciones sobre la reforma de los funcionarios de habilitación estatal", en El Consultor de los Ayuntamientos y de los Juzgados, nº 9, 2009, pp. 1311-1328; y también a FUENTETAJA PASTOR, J.A., "La función pública local ante el Estatuto básico del Empleado Público", en Anuario de Derecho Municipal, $\mathrm{n}^{\circ} 1,2007$, pp. 59-85. 
El texto original del artículo 92.2 (actual art. 92.3) de la Ley 7/1985 era el siguiente,

Son funciones públicas, cuyo cumplimiento queda reservado exclusivamente a personal sujeto al Estatuto funcionarial, las que impliquen ejercicio de autoridad, las de fe pública y asesoramiento legal preceptivo, las de control y fiscalización interna de la gestión económico-financiera y presupuestaria, las de contabilidad y tesorería y, en general, aquellas que, en desarrollo de la presente Ley, se reserven a los funcionarios para la mejor garantía de la objetividad, imparcialidad e independencia en el ejercicio de la función.

Vemos que se reservaban funciones al personal funcionario en su conjunto (curiosamente ya preveía la Ley, con la inocencia de la cercanía temporal de aquella flamante Constitución, la existencia de un Estatuto que tardaría en llegar).

Con la aprobación del EBEP y si bien -y para disgusto de los profesionales del ámbito local- no se prodigó realmente en regular las bases del régimen del empleo en las Entidades Locales, sí quiso establecer en su Disposición Adicional Segunda algunos elementos definidores, copiando básicamente el contenido del artículo 92 de la Ley 7/1985, aunque centrándose en los habilitados nacionales (que ahora se llamarían estatales). En fin, unificó en esa Disposición las reglas generales de las funciones reservadas a los funcionarios, así como unas nuevas normas para los habilitados, que antes se encontraban dispersas, derogando expresamente el artículo 92 citado, con el alcance establecido por la Disposición Final Cuarta.

Con ello, el EBEP disponía en la citada Disposición Adicional Segunda, punto 1.1 , que,

Son funciones públicas, cuyo cumplimiento queda reservado exclusivamente a funcionarios, las que impliquen ejercicio de autoridad, las de fe pública y asesoramiento legal preceptivo, las de control y fiscalización interna de la gestión económico-financiera y presupuestaria, las de contabilidad y tesorería.

Como vemos, prácticamente la misma redacción, salvo por lo que respecta a la omisión del último inciso, lo que parece cerrar la puerta al establecimiento de otras funciones reservadas, acotándolas única y exclusivamente a las que hemos visto, aunque hemos de decir que aquella clausula de cierre parecía más bien pretender supeditar el establecimiento de funciones reservadas a la garantía de la objetividad, imparcialidad e independencia de los funcionarios más que al contra- 
rio, otorgar dichas funciones "especiales" a los funcionarios precisamente por tener garantizados dichos principios.

Finalmente, la Ley 27/2013 ha venido a cambiar de nuevo la situación, invirtiéndola en cierto sentido, e incluyendo el elemento distorsionador del que hablábamos. Ha derogado la Disposición Adicional Segunda del EBEP al asumir la modificación del régimen local, deseando agruparlo en la Ley 7/1985, lo cual nos parece más acertado que lo que hizo el legislador con el amago de regulación a través de una adicional. Por otro lado, ha dado nuevo contenido al artículo 92 de la Ley 7/1985, del que nos interesa el apartado 3,

Corresponde exclusivamente a los funcionarios de carrera al servicio de la Administración local el ejercicio de las funciones que impliquen la participación directa o indirecta en el ejercicio de las potestades públicas o en la salvaguardia de los intereses generales. Igualmente son funciones públicas, cuyo cumplimiento queda reservado a funcionarios de carrera, las que impliquen ejercicio de autoridad, y en general, aquellas que en desarrollo de la presente Ley, se reserven a los funcionarios para la mejor garantía de la objetividad, imparcialidad e independencia en el ejercicio de la función.

Vemos que se han querido utilizar elementos tanto del artículo 9.2 EBEP para unificar contenidos al definir las funciones reservadas con carácter general, cuanto del artículo 92.2 de la Ley 7/1985 original, recuperando el inciso final al permitir el establecimiento por ley de otras de esas funciones.

\section{EL GAMBIO EN LA GONFIGURACIÓN SUBJETIVA DE LAS FUNCIONES RESERVADAS A LOS FUNGIONARIOS LOCA- LES}

Pero la novedad más significativa que introduce el legislador racionalizador en el actual artículo 92.3 de la Ley 7/1985, como ya habíamos anunciado, se encuentra en la restricción, tanto de las funciones reservadas en general como en las que se reserven específicamente a los funcionarios "de carrera". ¿Por qué esta apostilla?

Ciertamente, en la tramitación parlamentaria no hemos encontrado ninguna mención a esta novedad y el texto del apartado se mantuvo indemne desde el principio.

No parece entenderse muy bien el sentido de esta reforma, pues rompe con el elemento diferenciador entre funcionarios y laborales al establecer ahora la dis- 
tinción dentro de la misma función pública en una cuestión que era pacífica, pareciendo vaciar de contenido las funciones de los interinos cuando de acuerdo con lo dispuesto en el artículo 10.1 EBEP, que es de carácter básico, sustituyen o cubren plazas propias de funcionarios de carrera.

Efectivamente, dicho artículo establece que son funcionarios interinos los que, "por razones expresamente justificadas de necesidad y urgencia, son nombrados como tales para el desempeño de funciones propias de funcionarios de carrera", para continuar listando los casos en que puede contarse con este tipo de personal ${ }^{15}$.

Cabría preguntarse si esta modificación de la Ley 7/1985 es simplemente una cuestión de forma (pues no cabe duda de que es toda una novedad en ese apartado, que por otro lado es casi un "corta y pega" entre el EBEP y la redacción original del artículo 92.2 de la Ley $7 / 1985$, como ya dijimos) o se trata de un matiz intencional para dar relevancia a los funcionarios con plaza y evitar con ello el constante recurso a funcionarios interinos.

Como mera cuestión de forma tal vez podría considerarse hecha a efectos de conseguir una simple concordancia con el título del Capítulo II en que se inserta dicho artículo (Disposiciones comunes a los funcionarios de carrera), y por el hecho de no venir tan siquiera mencionada en la "nota explicativa" sobre la Ley 27/2013 emitida por el Ministerio de Hacienda y Administraciones Públicas $^{16}$, pero consideramos que no puede ser así pues ese mismo título ya existía en la redacción original de la Ley 7/1985 y además el epígrafe del artículo 92 dado por la Ley 27/2013 (antes no tenía ninguno) se refiere a los "Funcionarios al servicio de la Administración local", con lo que incluye también a los interinos.

La opción de dar relevancia a los funcionarios de carrera para evitar abusos no parece descabellada, toda vez que el legislador siempre ha sido muy reticente con quienes han aprovechado los resquicios legales para introducir personas de su entorno o burlar simplemente el espíritu de las normas en su provecho, algo por desgracia demasiado habitual en nuestra Administración. La posibilidad de

15 “a) La existencia de plazas vacantes cuando no sea posible su cobertura por funcionarios de carrera. b) La sustitución transitoria de los titulares. c) La ejecución de programas de carácter temporal. d) El exceso o acumulación de tareas por plazo máximo de seis meses, dentro de un periodo de doce meses".

${ }^{16}$ Nota explicativa de la reforma local publicada el 5 de marzo de 2014, que puede consultarse en el portal web del Ministerio de Hacienda y Administraciones Públicas: http://www.minhap.gob.es 
nombrar funcionarios interinos mediante procedimientos más ágiles, en palabras del artículo 10 EBEP, y en ocasiones menos rigurosos, así como la propia situación de temporalidad, hacen plausible esta interpretación. Empero, hemos de reconocer que no parece compadecerse muy bien con el artículo 10.1 EBEP y con el servicio que presta este tipo de personal, imprescindible como dijimos, para cubrir plazas de funcionarios de carrera en casos de urgencia.

Otra interpretación que parece más preocupante es si se está tratando de vaciar de contenido la función de los interinos, con lo que nos encontraríamos con una ilegalidad sobrevenida en las funciones que desempeñan y que impliquen dicha reserva, lo cual llevaría a la nulidad de cuantos actos dictasen a partir de la entrada en vigor de la Ley 27/2013 e incluso a responsabilidad administrativa o penal.

Si bien no podemos dudar de que el inciso se ha introducido por alguna razón, no creemos que sea ésta última la intención del legislador, comenzando porque la figura del funcionario interino no sólo se mantiene en el EBEP sino que resulta imprescindible para el buen desarrollo de la actividad administrativa ${ }^{17} \mathrm{y}$ son más los problemas prácticos que produciría esta interpretación que lo que se pretenda resolver con el inciso.

Por otro lado, se podría considerar que se trata de evitar que funcionarios interinos ejerzan funciones de Secretaría, Intervención o Tesorería, propias de habilitados, y que por sus características requieren de un personal permanente y con unos requisitos de acceso especiales. Esto resulta bastante lógico si consideramos las reticencias que hemos señalado pueden existir respecto de los interinos y lo delicado de los puestos de habilitación nacional. Pero enseguida encontramos que la restricción a los de carrera se extiende a todo tipo de funciones reservadas y no sólo a las que ejerce este tipo de funcionarios o a las que impliquen ejercicio de la autoridad.

Sólo habría que imaginar el descontrol en tantas Entidades Locales si de la noche a la mañana miles de interinos dejaran de poder ejercer funciones reservadas, más si entre ellos se encuentran quienes cubren plazas de habilitados nacionales. Además, ¿quién, si no, podría sustituir a los funcionarios de carrera con funciones reservadas en casos de bajas, vacantes, etc.?

${ }^{17}$ La STS de 12 de febrero de 1999 (Sala $7^{\text {a }}$. Recurso 5635/1998) llegó a establecer como doctrina legal que en casos de urgente necesidad se puede incluso convocar plazas de policías locales interinos. 
Por último, no podemos olvidar que la reserva de funciones nos indica que éstas sólo las pueden ejercer los funcionarios (de carrera en el ámbito local) pero que quedan otras muchas, no reservadas, que también podría desempeñar el personal funcionario. Es decir, los funcionarios no están sólo para ejercer potestades públicas (entendidas aquí en el sentido general de funciones reservadas) sino que más bien éstas sólo pueden ser desempeñadas por funcionarios. Así pues, los interinos podrían cubrir plazas funcionariales no revestidas de esa reserva, como por ejemplo, de auxiliares, administrativos, de profesiones y oficios... Creemos que ésta sería una interpretación más plausible y acorde con la regla básica del artículo 10.1 EBEP, aunque el legislador quizás debería haber sido más claro a la hora de redactar el artículo 92.3 de la Ley 7/1985. No deja de ser curioso que dicha restricción se haya hecho sólo respecto del personal de las entidades locales y no se haya querido modificar el EBEP en el mismo sentido para dotar de mayor uniformidad al sistema ${ }^{18}$.

Sin embargo, esta interpretación no resuelve la duda que se plantea con las situaciones existentes actualmente en que, con base en la propia redacción del artículo 10.1 EBEP, existen miles de puestos de interinos sustituyendo, no ya sólo a habilitados, sino cubriendo otros muchos puestos también reservados aunque menos esenciales en la Administración Local. La cuestión podría quedar en el aire pues no se trata, ni mucho menos, de cesarlos de la noche a la mañana, dejando a la Administración desnutrida de un importante capital humano, y por lo que estamos viendo no parece que vaya a tener consecuencias, quedando como una simple formalidad o apostilla sin apenas efectos prácticos, pues en otro caso suponemos que habría tenido mayor relevancia o su inclusión en la mencionada "nota aclaratoria" por los importantes efectos que podría producir en nuestro sistema local de función pública. Sin perder de vista que no existiría otra forma de cubrir plazas de funcionarios de carrera con funciones reservadas.

\section{CONGLUSIONES}

La doctrina y la Jurisprudencia han venido a coincidir en que las funciones consideradas reservadas por implicar ejercicio de potestades públicas, de autoridad, y en general la "participación directa o indirecta en el ejercicio de las potestades públicas o en la salvaguardia de los intereses generales" son la nota dis-

\footnotetext{
${ }^{18}$ Si bien entendemos que la Ley 27/2013 no es el lugar más apropiado para realizar esa modificación en el EBEP aunque haya derogado la Disposición Adicional Segunda, lo que es lógico por razón de la materia.
} 
tintiva entre los dos grandes grupos de personas al servicios de éstas: funcionarios y laborales, y que sólo los funcionarios pueden llevarlas a cabo.

Sin embargo, la restricción dentro del propio régimen estatutario funcionarial del ejercicio de aquellas funciones sólo a los de carrera ha introducido un elemento cuanto menos curioso y sin duda distorsionador de una situación largamente pacífica.

Son varias las interpretaciones posibles, pero ese cambio en la legislación especial de régimen local al margen de la regla básica que mantiene el EBEP de la posibilidad de reserva a todos los funcionarios en general, sigue planteando dudas y nos resistimos a creer totalmente que sea una mera cuestión formal, pareciendo la tesis más plausible que el legislador ha querido referirse con tal limitación a que los funcionarios interinos sólo podrán cubrir plazas propias de los de carrera cuando no impliquen el ejercicio de dichas funciones reservadas.

Sin embargo, ello no despeja la cuestión de que resultaría del todo punto inviable cesar a todos los interinos que cubren plazas con funciones de carácter reservado y sobre todo que se estaría impidiendo la sustitución o cobertura de plazas con funciones reservadas.

En fin, nos tememos que finalmente el inciso "de carrera" ha quedado en una simple cuestión semántica que ha pasado con más pena que gloria por falta de una redacción clara y porque no ha habido hasta el momento ninguna reacción al mismo.

\section{BIBLIOGRAFÍA}

GANTERO MARTÍNEZ, J., "Criterios para la clasificación del empleado público: ¿funcionario o laboral?”, en Revista Vasca de Gestión de Personas y Organizaciones Públicas, n ${ }^{\circ}$ 5, 2013, pp. 82-99.

DE SANDE PÉREZ BEDMAR, M., Empleo y prestación de servicios en la Administración Pública, Valladolid, Lex Nova, 2006.

ESCRIBANO TESTAUT, P., Fundamentos del sistema constitucional de empleo público (un estudio de los artículos 103.3 y 23.2 de la Constitución), Universidad Autónoma de Madrid, Tesis Doctoral, 1998. 
FUENTETAJA PASTOR, J.A., "La función pública local ante el Estatuto básico del Empleado Público", en Anuario de Derecho Municipal, nº 1, 2007, pp. 59-85.

INAP, Estatuto básico del empleado público: informe de la Comisión, Madrid, INAP, 2005.

MAIRAL JIMÉNEZ, M., El derecho constitucional a la igualdad de tratamiento juridico en el empleo público: (un estudio de los problemas jurídicos derivados de la dualidad de regimenes...), Universidad de Granada, Tesis Doctoral, 1990.

VERA TORRECILLAS, R.J., "Las funciones reservadas y el Estatuto Básico del Empleado Público: algunas consideraciones sobre la reforma de los funcionarios de habilitación estatal", en El Consultor de los Ayuntamientos y de los Fuzgados, n 9, 2009, pp. 1311-1328. 